\title{
Adrenergic Enhancement of Inhibitory Transmission in the Accessory Olfactory Bulb
}

\author{
Ricardo C. Araneda and Stuart Firestein \\ Department of Biological Sciences, Columbia University, New York, New York 10027
}

\begin{abstract}
Noradrenergic modulation of dendrodendritic synapses between the mitral and granule cells in the accessory olfactory bulb (AOB) is postulated to play a key role in the formation of memory in olfactory-mediated behaviors. Current models propose that noradrenaline (NA) increases excitation of mitral/tufted cells (M/TCs) by decreasing the release of GABA from granule cells. However, surprisingly little is known about the actions of NA at the cellular level in the AOB. Here, in recordings from AOB slices, we show that NA decreases the firing frequency of M/TCs in response to stimulation. This effect is attributable to an increase in the GABA inhibitory input to M/TCs. Application of NA $(10 \mu \mathrm{M})$ produced an $\sim 20$-fold increase in the frequency of GABA-induced miniature IPSCs (mIPSCs) without changing their amplitude. A pharmacological analysis indicated that the increase in mIPSCs frequency results from activation of $\alpha 1$ adrenergic receptors. In addition to increasing the mIPSC frequency, NA also potentiated GABA inhibitory currents induced by direct stimulation of granule cells. Together, our results suggest that NA increases the release of GABA from granule cells by acting on presynaptic receptors. Thus, the role of the noradrenergic activity in the $\mathrm{AOB}$ may be opposite than suggested previously: we find that the overall effect of NA in the AOB is inhibition of M/TCs.
\end{abstract}

Key words: olfactory; memory; mating; noradrenaline; dendrodendritic; presynaptic

\section{Introduction}

In most mammals, there are two anatomically independent, although integrated, olfactory systems: the main olfactory system, which is concerned primarily with environmental odors such as those of predators or food, and the vomeronasal system, which modulates behaviors such as mating and aggression (Firestein, 2001; Halpern and Martinez-Marcos, 2003). Sensory neurons in the main olfactory system send their axons to targets in the main olfactory bulb (MOB), whereas vomeronasal sensory neurons send their axons to a well demarcated dorsal and posterior region of the olfactory bulb, the accessory olfactory bulb (AOB). In both systems, axons of sensory cells synapse onto the dendrites of second-order projection neurons known as mitral and tufted cells (M/TCs) (Shepherd and Greer, 1998).

In both the $\mathrm{AOB}$ and $\mathrm{MOB}$, a network of inhibitory interneurons, the periglomerular and granule cells, forms widespread synaptic interactions with the axon terminals of the sensory cells and the dendrites of M/TCs. Notable among these synapses is the dendrodendritic reciprocal synapse between M/TCs and granule cells (Shepherd and Greer, 1998). First characterized in the MOB (Rall et al., 1966; Nicoll, 1969), this synapse consists of excitatory glutamatergic input from M/TCs to granule cells, which induces the release of GABA from the dendrites of granule cells, in turn

Received Nov. 7, 2005; revised Jan. 19, 2006; accepted Feb. 9, 2006.

This work was supported by a National Institutes of Health R03 grant (R.C.A.). We thank Denise Wiedl and Alycia Monopoli for their help with some of the data analysis and members of the Firestein laboratory for their helpful comments on this manuscript.

Correspondence should be addressed to Ricardo C. Araneda at the above address. E-mail: rca23@columbia.edu. DOI:10.1523/JNEUROSCI.4768-05.2006

Copyright $\odot 2006$ Society for Neuroscience $\quad$ 0270-6474/06/263292-07\$15.00/0 inhibiting M/TCs (Isaacson and Strowbridge, 1998; Schoppa et al., 1998). This synapse has been investigated thoroughly in the MOB (Schoppa and Urban, 2003), but it has received less attention in the AOB in which it is presumed to serve a similar essential role in the processing of olfactory information (Hayashi et al., 1993; Jia et al., 1999; Taniguchi and Kaba, 2001).

The olfactory bulb receives an extensive afferent innervation that acts to modulate the flow of olfactory sensory information (Shepherd and Greer, 1998). Dendrodendritic synapses are a likely target for this modulation. For example, in the AOB, modulation of dendrodendritic synapses by noradrenergic afferent fibers has been postulated to play a key role in the formation of the memory for the stud during mating in mice (Kaba and Nakanishi, 1995; Brennan and Keverne, 1997; Brennan, 2004). Both the $\mathrm{MOB}$ and $\mathrm{AOB}$ receive an extensive noradrenergic projection (Shipley et al., 1985; McLean et al., 1989), and, during mating, noradrenaline (NA) levels in the bulb are increased (Rosser and Keverne, 1985; Brennan et al., 1995). If a recently mated female is exposed to the "odor" of a male different from the stud, exposure to this foreign male odor results in failure of implantation of the embryo, an outcome known as the Bruce effect (Bruce, 1960). Current models propose that NA inhibits the release of GABA from granule cells in the AOB (Kaba and Nakanishi, 1995; Brennan, 2004). This decrease in GABA, in turn, has an excitatory effect on M/TCs. However, these models mostly rely on the reported excitatory actions of NA in the MOB.

In light of the important function of the noradrenergic system in the formation of olfactory memory and its potential role in the $\mathrm{AOB}$, we investigated the actions of NA on the output neurons of the AOB at a cellular level. We find that NA produces an unexpected inhibition of M/TCs in the AOB. This effect is attributable 
to an increase in the inhibitory GABAergic transmission at dendrodendritic synapses. We find that NA, acting on $\alpha 1$ adrenergic receptors, greatly enhances both the frequency of miniature IPSCs (mIPSCs) in M/TCs and the evoked release of GABA from granule cells.

\section{Materials and Methods}

Slice preparation. Experiments were performed in AOB slices obtained from 2- to 6-week-old C57BL/6 mice. Both male and female mice were used in our studies because we did not find any gender differences in the effects of NA. Animals were anesthetized by an intraperitoneal injection of a ketamine/xylazine solution and decapitated. Brain slices were prepared in a modified artificial CSF (sucrose ACSF) of the following composition (in mM): 222 sucrose, $27 \mathrm{NaHCO}_{3}, 1.25 \mathrm{NaH}_{2} \mathrm{PO}_{4}, 3 \mathrm{KCl}, 1$ $\mathrm{CaCl}_{2}$, and $3 \mathrm{MgCl}_{2}$. The whole brain was quickly removed and placed in oxygenated ice-cold sucrose ACSF. A block of tissue, containing part of the frontal lobes and the olfactory bulbs, was glued with cyanoacrylate to a microslicer stage and bathed in chilled sucrose ACSF. Sagittal sections $(250-300 \mu \mathrm{m})$ of the olfactory bulb, containing the AOB, were sliced using a vibrating microslicer (Ted Pella, Redding, CA). The slices were then transferred to an incubation chamber containing normal ACSF (see below) and left to recuperate first at $37^{\circ} \mathrm{C}$ for $30 \mathrm{~min}$ and then at room temperature for another hour. In all experiments, unless otherwise indicated, the extracellular solution is ACSF of the following composition (in mM): $125 \mathrm{NaCl}, 25 \mathrm{NaHCO}_{3}, 1.25 \mathrm{NaH}_{2} \mathrm{PO}_{4}, 3 \mathrm{KCl}, 2 \mathrm{CaCl}_{2}, 1 \mathrm{MgCl}_{2}, 3$ myo-inosytol, 0.3 ascorbic acid, $2 \mathrm{Na}$-pyruvate, and 15 glucose, continuously oxygenated $\left(95 \% \mathrm{O}_{2}\right.$ and $\left.5 \% \mathrm{CO}_{2}\right)$ to give a pH 7.4 (osmolarity of $\sim 305 \mathrm{mOsm}$ ).

Electrophysiological recordings. Slices were placed in a submerged recording chamber mounted on the stage of a Nikon (Melville, NY) E600FN, fixed-stage, upright microscope, fitted with differential interference contrast optics. Slices were observed with a $40 \times$ waterimmersion objective, and M/TCs were recognized by their morphology and position in the slices; in the $\mathrm{AOB}$, the lateral olfactory tract (LOT) separates the granule cell layer from the M/TCs and glomerular layers (Takami and Graziadei, 1991; Meisami and Bhatnagar, 1998). All experiments were performed at room temperature.

Standard patch pipettes (3-7 M $\Omega$ resistance) were pulled on a horizontal puller. The recording electrode was filled with different internal solutions depending on the experimental protocol. For current-clamp experiments, the internal solution had the following composition (in mM): $135 \mathrm{~K}$-gluconate, $10 \mathrm{NaCl}, 10 \mathrm{KCl}, 10$ HEPES-Na, $2.5 \mathrm{ATP}$, and 0.3 GTP adjusted to $\mathrm{pH} 7.3$ with $\mathrm{KOH}$. In voltage-clamp experiments, the internal solution had the following composition (in $\mathrm{mM}$ ): 135 Csgluconate or $\mathrm{CsCl}, 10 \mathrm{NaCl}, 10 \mathrm{KCl}, 10$ HEPES-Na, 2.5 ATP, and 0.3 GTP adjusted to $\mathrm{pH} 7.3$ with the appropriate base. The osmolarity of the internal solution was adjusted to 290-305 mOsm. During the recordings, the access resistance was continuously monitored with hyperpolarizing voltage pulses. Cells were discarded if input resistances changed by $>20 \%$ during the course of an experiment. Single-cell ionic currents (voltage clamp) and voltage (current clamp) were recorded using an Axopatch-1D patch-clamp amplifier (Molecular Devices, Union City, CA).

Data analysis. Data was acquired using the Pulse software (InstruTech, Port Jefferson, NY) and digitized at $5 \mathrm{kHz}$ using an ITC-16 interface (InstruTech, Port Jefferson, NY). Data analysis was performed using macros written for the Igor Pro software (WaveMetrics, Lake Oswego, OR) and the Mini 60 software (Synaptosoft, Decatur, GA). For the data in Figures 1 and 2, we calculated the rate of firing (frequency) for time segments of $1 \mathrm{~min}$ before and after NA. We quantified the noise with the RMS (root mean square) function in Igor Pro, using segments of $20 \mathrm{~s}$, before and after NA. The kinetic analysis of mIPSCs shown in Figure 3 was performed in segments of $8-15 \mathrm{~min}$ for control and 1.5-2 min after NA.

All drugs were bath applied except when noted (see below). The volume of the chamber and the speed of perfusion allowed for full exchange of the solution in $<1 \mathrm{~min}$. Antagonists were applied for at least $10 \mathrm{~min}$. For mIPSC recordings, the NMDA receptor antagonist D,L-2-amino-5 phosphonopentanoic acid (APV) $(100 \mu \mathrm{M})$, the AMPA receptor antagonist 2,3-dihydroxy-6-nitro-7-sulfamoybenzo- $(f)$-quinoxaline (NBQX)
$(10 \mu \mathrm{M})$, and the voltage-gated Na channel blocker tetrodotoxin (TTX) ( $1 \mu \mathrm{M})$ were included in the bathing solution. The presence of LOT between the granule cell and M/TC layers prevented us from directly stimulating granule cells with current, because this would also have induced antidromic stimulation of M/TCs. For this reason, we chose to stimulate granule cells by local application of glutamate $(1 \mathrm{~mm})$ through pressure ejection (Picospritzer; General Valve, Fairfield, NJ) from a patch pipette. The pipette was positioned above the soma of granule cells that were in the same radius as the recorded M/TC. Because NA also increased GABA IPSCs, we measured the charge associated with the glutamateinduced current. This was done by integrating the current over a $1 \mathrm{~s} \mathrm{time}$ window before (baseline) and during the glutamate-induced IPSCs for the control condition and in the presence of NA. To stimulate the axon terminals of vomeronasal sensory neurons, we placed a bipolar electrode (tips, $130 \mu \mathrm{m}$ apart; Frederick Haer Company, Bowdoinham, ME) in the vomeronasal nerve $(\mathrm{VN})$ layer. Square current pulses were commanded with the HEKA Elektronik (Lambrecht/Pfalz, Germany) software from a stimulus isolator unit (A.M.P.I., Jerusalem, Israel). The stimulus intensity $(20-250 \mu \mathrm{A}, 50 \mu \mathrm{s})$ was adjusted until the evoked EPSP elicited action potentials in the recorded M/TC. These stimulating conditions produced one to several action potentials. We measured the number of stimulus-evoked spikes, as well as the latency to the first action potential during the trials occurring $2 \mathrm{~min}$ before and $2 \mathrm{~min}$ after the application of phenylephrine (PE).

All drugs were purchased from Tocris Cookson (Bristol, UK) except for NA and bicuculline, which were purchased from Sigma (St. Louis, MO). Statistical differences were assessed by the paired $t$ test and the Kolmogorov-Smirnov test. Values reported correspond to results from at least three different trials, and error bars indicate the SEM.

\section{Results}

Several studies have indicated that the overall effect of noradrenergic modulation in the MOB is excitatory (Jahr and Nicoll, 1982; Trombley and Shepherd, 1992; Mouly et al., 1995; Ciombor et al., 1999; Hayar et al., 2001) (but see McLennan, 1971; Perez et al., 1987; Mouly et al., 1995). These effects include direct depolarization of M/TCs and a decrease in the inhibitory activity at dendrodendritic synapses. Although a similar mechanism has been postulated to occur in the $\mathrm{AOB}$, only a few studies have addressed the role of the adrenergic system in AOB (Kaba and Keverne, 1988; Brennan et al., 1995; Kaba and Huang, 2005).

\section{Noradrenaline inhibits mitral/tufted cells in the AOB}

In a first set of experiments, we recorded the effects of NA on spontaneously active M/TCs in cell-attached patches (Fig. $1 \mathrm{~A}$ ). Under these conditions, we could record the activity of the cell in the absence of intracellular dialysis. Surprisingly, we found that bath application of NA $(10 \mu \mathrm{M})$ reduced the frequency of firing by $\sim 75 \%$ in five of six cells tested (control, $2.4 \pm 0.6 \mathrm{~Hz}$; after NA, $0.8 \pm 0.4 \mathrm{~Hz} ; p<0.005$ ) (Fig. $1 B$ ). In the remaining cell, the frequency of firing was unchanged. The effect of NA had a relatively slow onset $(>40 \mathrm{~s})$, and the decrease in firing frequency was accompanied by an increase in the size of the spikes, suggesting a hyperpolarization of the cells (Fig. 1C). In current clamp with $\mathrm{K}$-gluconate in the pipette (see Materials and Methods), application of NA resulted in a small hyperpolarization $(4.1 \pm 0.9 \mathrm{mV}$; $n=9$ ) in 9 of 11 cells (Fig. $2 A$ ). One cell exhibited no change in membrane potential, and the remaining cell was depolarized. The hyperpolarization developed with a similar onset as the decrease in firing frequency, which had been observed in the cell-attached patch recordings. We tested the effect of NA on the frequency of firing in response to a depolarizing current pulse $(500 \mathrm{~ms}, 100$ $\mathrm{pA})$. In seven of eight cells, NA produced a decrease in the number of spikes elicited by the stimulus (Fig. $2 B$ ), whereas the remaining cell was unaffected. Additionally, NA increased the syn- 
A

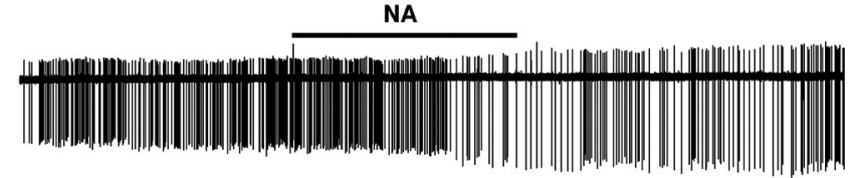

B

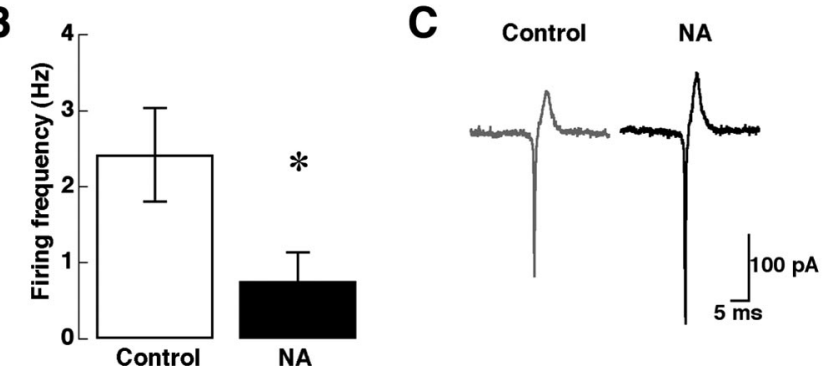

Figure 1. Noradrenaline decreases the frequency of firing of $M / T C s$ in cell-attached patches. A, Bath application of NA (10 $\mu \mathrm{m}, 2 \mathrm{~min}$ ) reduced the frequency of firing in M/TCs that were spontaneously active (control, $1.2 \mathrm{~Hz}$; after NA, $0.5 \mathrm{~Hz}$ in this cell). The effect of NA has a slow onset $(>40 \mathrm{~s}) . \boldsymbol{B}$, The average frequency of firing was significantly reduced after the application of NA (control, $2.4 \pm 0.6 \mathrm{~Hz}$; after NA, $0.8 \pm 0.4 \mathrm{~Hz} ;{ }^{*} p<0.006 ; n=5$ ). C, The size of the spikes was increased after the application of NA, suggesting that the cell hyperpolarized (selected spikes from the cell shown in $A$ ). The pipette holding potential was $0 \mathrm{mV}$.

A

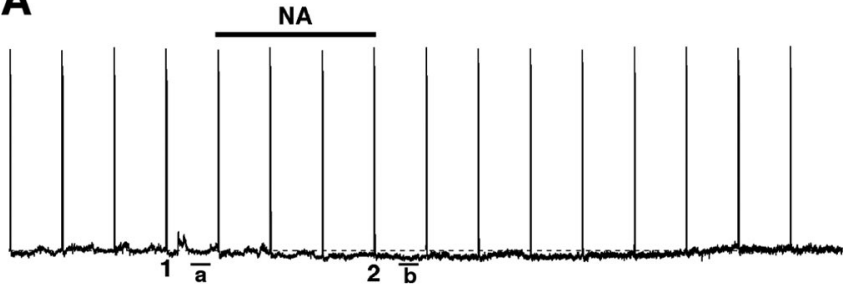

B

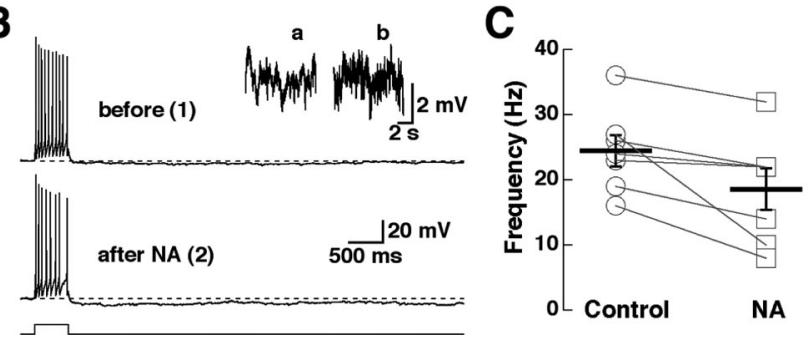

Figure 2. Noradrenaline decreases the frequency of firing during a depolarizing current pulse. $\boldsymbol{A}$, NA produced a small hyperpolarization of M/TCs, $2.5 \mathrm{mV}$ in this cell; the dotted line represents the resting membrane potential $(-61 \mathrm{mV})$. The vertical lines are compressed trains of spikes (see below). $B$, Cells were stimulated with a depolarizing current pulse (100 pA, 500 $\mathrm{ms})$. NA decreased the number of spikes elicited by the stimulus. Notice the small afterhyperpolarization at the end of the depolarizing pulse attributable to dendrodendritic inhibition, which was increased by NA in this cell. Inset, NA also increased the synaptic noise (this is the same cell shown in $\boldsymbol{A})$. $\boldsymbol{C}$, The firing frequency was decreased in seven of eight cells tested. Average control, $24.4 \pm 2.4 \mathrm{~Hz}(\bigcirc)$; after NA, $18.6 \pm 3.2 \mathrm{~Hz}(\square) ; p<0.01$, one-tailed $t$ test.

aptic noise (control, $2.98 \pm 0.09$; after NA, $3.17 \pm 0.06 \mathrm{mV} ; n=$ $5 ; p<0.05$ ) (Fig. 2B, inset). Under control conditions, the spike frequency elicited by the depolarizing pulse in M/TCs was variable (16-36 Hz; mean, $24.4 \pm 2.4 \mathrm{~Hz}$ ) (Fig. $2 C$ ). However, NA produced a significant decrease in the frequency of spikes during the stimulus (mean, $18.6 \pm 2.2 \mathrm{~Hz} ; p<0.03$ ). The decrease in firing frequency was not correlated to the degree of hyperpolarization induced by NA (data not shown). Together, these results suggest that, in the AOB, NA exerts an inhibitory action on $\mathrm{M} / \mathrm{TC}$. This effect appears likely to be mediated by an increase in the inhibitory GABA input from granule cells, periglomerular cells, or both.
Noradrenaline enhances GABA mIPSC frequency

In dendrodendritic synapses of the olfactory bulb, glutamate released from M/TCs activates the release of GABA from granule and/or periglomerular cell dendrites. In turn, GABA, by acting on $\mathrm{GABA}_{\mathrm{A}}$ type receptors, inhibits M/TCs (Schoppa and Urban, 2003). We found that, in voltage-clamp recordings with high $\mathrm{Cl}^{-}$ internal solutions (see Materials and Methods), NA (3-30 $\mu \mathrm{M})$ produced a robust increase in the frequency of inhibitory currents in M/TCs (data not shown, but see Fig. 5). Therefore, to better analyze the effects of NA on GABA inhibitory currents, we recorded $\mathrm{mIPSC}$ in the presence of blockers of glutamate ionotropic receptors (NBQX, $10 \mu \mathrm{M}$; APV, $100 \mu \mathrm{M}$ ) while using TTX $(1 \mu \mathrm{M})$ to block action potential-dependent GABA release.

In recordings with Cs-gluconate in the electrode at $0 \mathrm{mV}$, GABA-induced mIPSCs were outward. Under control conditions, mIPSCs occurred at low frequency $(0.4 \pm 0.1 \mathrm{~Hz} ; n=6)$ and the amplitude histogram distributions exhibited multiple peaks (data not shown), with a mean amplitude of $20.8 \pm 2.1 \mathrm{pA}$. Bath application of NA $(10 \mu \mathrm{M}, 2 \mathrm{~min})$ produced a dramatic increase in the frequency of mIPSC $(10.8 \pm 1.1 \mathrm{~Hz} ; p<0.0002)$ (Fig. $3 A, C$, inset). The increase in mIPSC frequency induced by NA was slow in onset $(>1 \mathrm{~min})$ and lasted several minutes $(>10$ min). Both the basal and the NA-induced mIPSCs were completely blocked by bicuculline $(20 \mu \mathrm{M})$ (Fig. $3 B)$ but not by the glycinergic antagonist strychnine (10 $\mu \mathrm{M}$; data not shown), indicating that the $\mathrm{GABA}_{\mathrm{A}}$ receptor type mediates these currents. The cumulative amplitude distribution showed a slight shift to the left in the presence of NA (Fig. $3 C$, left), but the average amplitude was not significantly affected $(17.1 \pm 1.9 \mathrm{pA} ; p>0.2)$ (Fig. $3 C$, inset). This shift in the cumulative amplitude distribution was probably attributable to the increased number of small-sized events. Moreover, NA did not affect the size of the response to GABA when directly applied to M/TCs (data not shown). Together, these results suggest that NA acts presynaptically to increase the release of GABA from dendrodendritic synapses.

\section{Noradrenaline enhances mIPSC frequency by activating of $\alpha 1$} adrenergic receptors

The $\alpha$ and $\beta$ adrenergic receptors are further divided into different subtypes (Zhong and Minneman, 1999). Thus, to determine the type of receptor involved in the stimulatory effect of NA on GABAergic transmission, we tested the ability of selective adrenergic agonists and antagonists to modify mIPSC frequency (Fig. $4)$. We found that the increase in mIPSCs frequency elicited by NA ( $10 \mu \mathrm{M} ; 0.9 \pm 0.2$ vs $8.6 \pm 2.2 \mathrm{~Hz} ; p<0.001)$ was mimicked by the $\alpha 1$ adrenergic agonist phenylephrine $(30 \mu \mathrm{M} ; 8.5 \pm 2.2 \mathrm{~Hz}$; $p<0.001)$. However, neither the $\alpha 2$ adrenergic agonist clonidine $(10 \mu \mathrm{M} ; 0.5 \pm 0.1 \mathrm{~Hz})$ nor the $\beta$ adrenergic agonist isoproterenol $(10 \mu \mathrm{M} ; 1.3 \pm 0.8 \mathrm{~Hz})$ affected mIPSC frequency. Moreover, the effect of NA could be completely blocked by the $\alpha 1$ adrenergic antagonist prazosin $(100 \mathrm{nM} ; 0.5 \pm 0.2 \mathrm{~Hz})$. Altogether, these results indicate that, in the $\mathrm{AOB}, \mathrm{NA}$ increases the release of GABA by activation of $\alpha 1$ adrenergic receptors.

\section{Noradrenaline increases the evoked release of GABA from granule cells}

Several studies indicate that granule cells, the main inhibitory neurons of the olfactory bulb, receive an important noradrenergic innervation from the locus ceruleus (Shipley et al., 1985). These cells thus are likely key targets for noradrenergic modulation. Therefore, to further understand the role of noradrenergic action in the AOB, we studied the effect of NA on the evoked release of GABA from granule cells. 
A

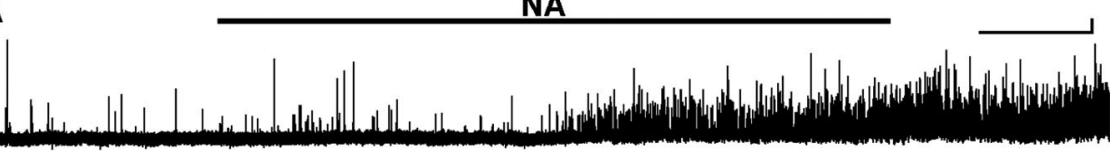

B

Control
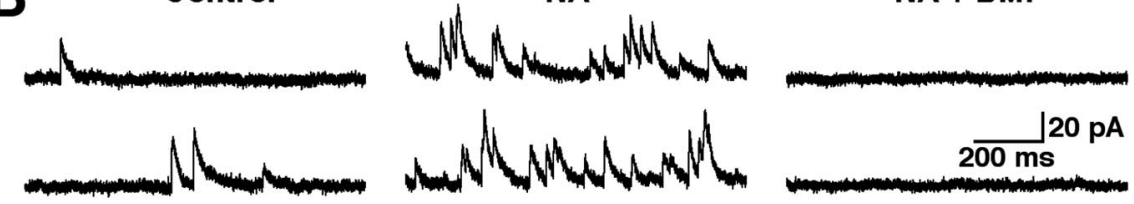

C

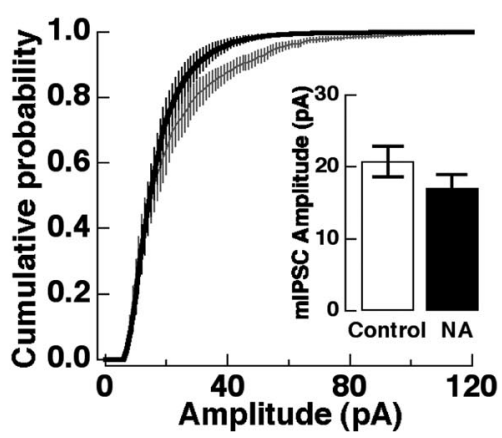

NA + BMI

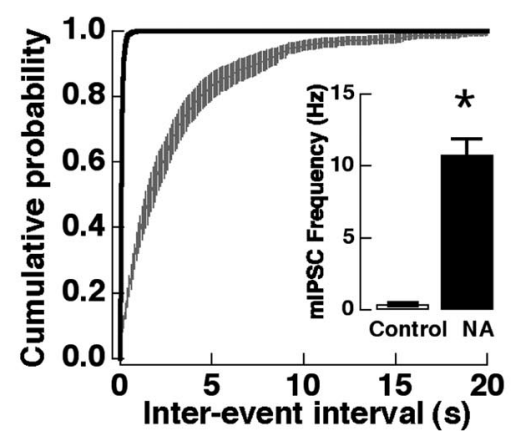

Figure 3. Noradrenaline increases the frequency of GABA mIPSCS. $A$, NA (10 $\mu \mathrm{m}, 2 \mathrm{~min})$ greatly increased the frequency of $\mathrm{mIPSC}$ in M/TCs recorded in the presence of TTX (1 $\mu \mathrm{M}), \mathrm{NBQX}(10 \mu \mathrm{M})$, and APV $(100 \mu \mathrm{M})$. Calibration: $20 \mathrm{pA}, 20 \mathrm{~s}$. $\boldsymbol{B}$, Selected traces for mIPSCs for the same cell shown in $A$. NA increased both the small- and large-amplitude mIPSCs (see Results). The effect of NA was completely blocked by the $\mathrm{GABA}_{\mathrm{A}}$ receptor antagonist bicuculline methiodide (BMl; $20 \mu \mathrm{M}$ ). C, Average cumulative amplitude (left) and inter-interval distributions (right) for the mIPSCs, control (gray) and in the presence of NA (dark thick line; $n=6$ ). Left, The cumulative amplitude shows a small shift to the left attributable to an increase in the frequency of small-sized mIPSCs. However, the average amplitude was not changed (control, $20.8 \pm 2.1 \mathrm{vs}$ $17.1 \pm 1.9 \mathrm{pA}$ in NA; inset bar graph). Right, The cumulative interevent distribution shows a shift to the left in the presence of NA resulting from the increase in frequency of $\operatorname{mIPSCS}\left(0.4 \pm 0.1 \mathrm{vs} 10.8 \pm 1.1 \mathrm{~Hz}\right.$; inset bar graph, $\left.{ }^{*} p<0.0002\right)$. The holding potential was $0 \mathrm{mV}$.

A

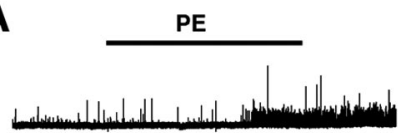

ISO

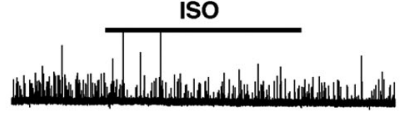

B

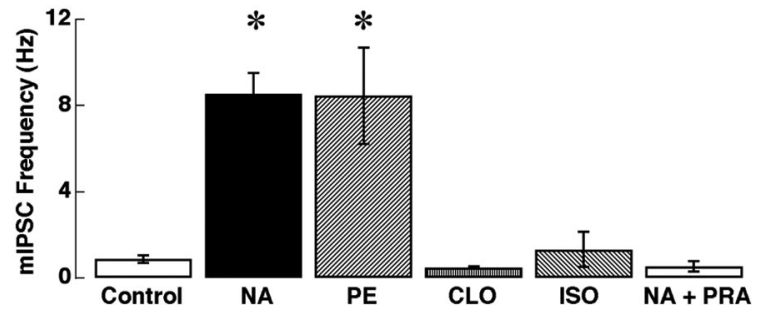

Figure 4. Noradrenaline increases the frequency of GABA mIPSCs by activating $\alpha 1$ adrenergic receptors. $\boldsymbol{A}$, The $\alpha 1$ adrenergic agonist PE $(30 \mu \mathrm{m})$ mimics the effect of NA. Neither the $\alpha 2$ adrenergic agonist clonidine (CLO; $10 \mu \mathrm{m})$ nor the $\beta$ adrenergic agonist isoproterenol (ISO; 10 $\mu \mathrm{m})$ modified the frequency of mIPSC. The $\alpha 1$ adrenergic antagonist prazosin (PRA; $100 \mathrm{~nm}$ ) completely blocked the effect of NA. The PE, clonidine, and isoproterenol records shown are from the same cell. $B$, The control average mIPSC frequency $(0.9 \pm 0.2 \mathrm{~Hz} ; n=15)$ was greatly increased by NA $\left(8.8 \pm 2.3 \mathrm{~Hz} ; n=4 ;{ }^{*} p<0.001\right)$ and by PE $\left(8.5 \pm 2.2 \mathrm{~Hz} ; n=4 ;{ }^{*} p<\right.$ $0.001)$, although it was unchanged by clonidine or isoproterenol $(0.5 \pm 0.1$ and $1.3 \pm 0.8 \mathrm{~Hz}$, respectively; both $n=3)$. The effect of NA was completely blocked by PRA $(0.5 \pm 0.2 \mathrm{~Hz} ; n=$ 4). The holding potential was $0 \mathrm{mV}$.
We focally stimulated granule cells by pressure ejecting glutamate from a patch pipette (1 mM, $100 \mathrm{~ms}$; see Materials and Methods). The stimulating pipette was positioned in the granule cell layer in the vicinity of the recorded M/TC. As shown in Figure 5, in recordings with a high $\mathrm{Cl}^{-}$ internal solution (at $-60 \mathrm{mV}$ ), stimulation with glutamate induced a barrage of inward postsynaptic currents in the M/TC. These inhibitory currents, which are produced when depolarized granule cells release GABA from dendrodendritic synapses, could be completely blocked by the $\mathrm{GABA}_{\mathrm{A}}$ receptor antagonist bicuculline $(20 \mu \mathrm{M} ; n=4)$ (Fig. $5 C$ ). Figure $5 B$ shows the averages for the evoked GABA currents before and after NA for the cell shown in Figure $5 A$ (seven pulses each). Both the baseline and the glutamateinduced IPSC frequency are enhanced in the presence of NA. Accordingly, we measured the charge (see Materials and Methods) before and during the glutamateinduced IPSCs. Under control conditions, the percentage increase from baseline in charge induced by glutamate was $35 \pm 7 \%$ (baseline, $87 \mathrm{nC} ; n=6$ ). Application of NA $(10 \mu \mathrm{M}, 2 \mathrm{~min})$ further increased the frequency of the currents and consequently the charge for the baseline (93 $\mathrm{nC})$, and the percentage increase in charge induced by the glutamate pulse was $69 \pm$ $13 \%$ ( $p<0.003$, one-tail $t$ test). Thus, in addition to the mIPSCs, NA also enhances the evoked release of GABA from granule cells. It is noteworthy that a focal application of NA via a patch pipette in the vicinity of the recorded M/TCs was sufficient to increase the MIPSC frequency, further suggesting an action at dendrodendritic synapse rather than at the soma of the granule cell's soma (data not shown).

The effect of noradrenaline is dependent on $\mathrm{Ca}^{2+}$ ions

To evaluate the contribution of voltage-dependent $\mathrm{Ca}^{2+}$ channels on the NA-induced increase in mIPSC frequency, we included the calcium channel blockers $\mathrm{Cd}^{2+}$ and $\mathrm{Ni}^{2+}$ in the external solution (each at $100 \mu \mathrm{M}$ ). As shown in Figure 6, addition of the blockers greatly reduced the effect of NA. Although NA significantly increased mIPSC frequency in control conditions (before, $0.8 \pm 0.4 \mathrm{~Hz}$; after NA, $7.7 \pm 1.9 ; p<0.02 ; n=5$ ) when $\mathrm{NA}$ was applied in the presence of $\mathrm{Cd}^{2+}$ and $\mathrm{Ni}^{2+}$, there was no significant change in mIPSC frequency (before, $0.5 \pm 0.1 \mathrm{~Hz}$; after NA, $1.3 \pm 0.7 ; p>0.3)$. These results suggest that the increase on mIPSC frequency induced by NA is dependent on $\mathrm{Ca}^{2+}$ influx through voltage-gated $\mathrm{Ca}^{2+}$ channels.

Activation of $\alpha 1$ adrenergic receptors inhibits activity of $\mathrm{M} /$ TCs in response to input from sensory neurons

Sensory neurons in the vomeronasal organ project their axons to the AOB via the VN. As in the MOB, these axons form excitatory synapses with the dendrites of M/TCs (Jia et al., 1999). Thus, the enhancement of inhibitory activity produced by $\alpha 1$ adrenergic receptor activation could also affect these postsynaptic responses. 
A -
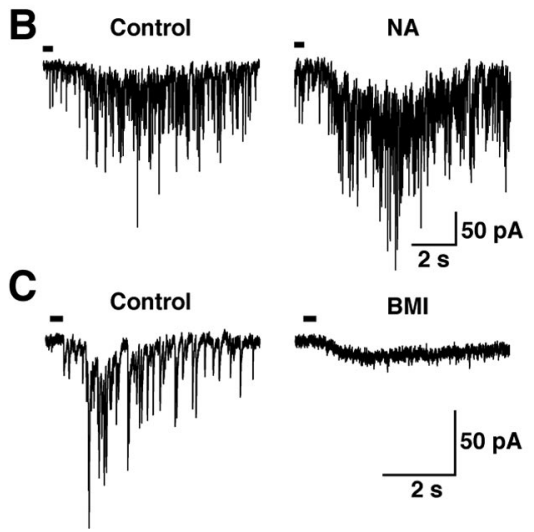

D

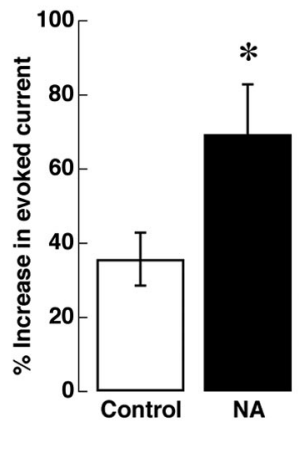

Figure 5. Noradrenaline increases the glutamate-evoked release of GABA. $\boldsymbol{A}, \mathrm{A}$ glutamate pulse $(1 \mathrm{~mm}, 100 \mathrm{~ms}$, every $30 \mathrm{~s})$ was used to stimulate granule cells. The glutamate-containing patch pipette was positioned in the granule cell layer, in the vicinity of the recorded M/TC. The glutamate pulse produced a barrage of GABA IPSCs, which were enhanced by NA (10 $\mu \mathrm{m}, 2$ $\mathrm{min}$ ). In this figure, the gap (20 s) between consecutive glutamate applications has been removed to better illustrate the effect of NA. $\boldsymbol{B}$, Average currents for glutamate-induced GABA (see below) currents before and after NA (7 pulses each) for the cell shown in $\boldsymbol{A}$. Both the baseline and the glutamate-induced IPSCs frequency were enhanced in the presence of NA. $C$, The glutamate-evoked IPSCs are completely blocked the $G_{A B A_{A}}$ receptor antagonist bicuculline (BMl; $20 \mu \mathrm{m} ; n=4)$. $\boldsymbol{D}$, The percentage increase in current induced by glutamate was higher in the presence of NA (control, $35 \pm 7 \%$; after NA, $69 \pm 13 \%$; ${ }^{*} p<0.003$, one-tail $t$ test; $n=6$ ). The holding potential was $-60 \mathrm{mV}$.
A

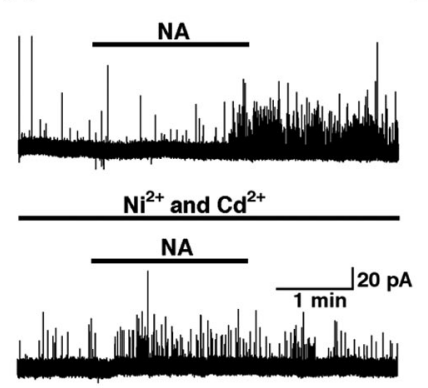

B

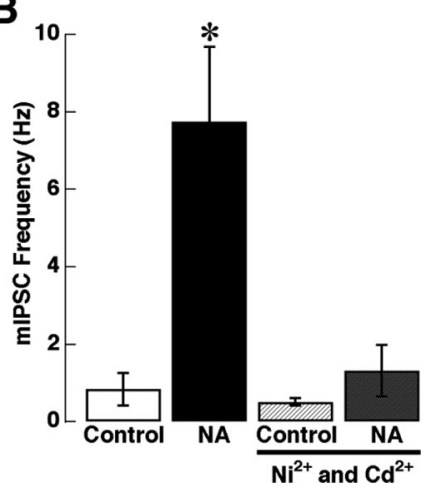

Figure 6. The noradrenaline-induced increase in mIPSC frequency is dependent on calcium ions. $A$, Effect of NA (10 $\mu \mathrm{M}, 2 \mathrm{~min})$ on mIPSC frequency in control (top) and in the presence of the calcium channel blockers $\mathrm{Cd}^{2+}$ and $\mathrm{Ni}^{2+}$ (bottom; each at $100 \mu \mathrm{m}$ ). In control conditions, NA greatly increased the frequency of mIPSC (before, $0.4 \mathrm{~Hz}$; after NA, $4.2 \mathrm{~Hz}$ ). In the presence of $\mathrm{Cd}^{2+}$ and $\mathrm{Ni}^{2+}$, the effect of NA was reduced (before, $0.2 \mathrm{~Hz}$; after NA, $0.8 \mathrm{~Hz}$ ). $\boldsymbol{B}$, The average mIPSC frequency after NA was significantly increased in control conditions (before, $0.8 \pm 0.4 \mathrm{~Hz}$; after $\left.\mathrm{NA}, 7.7 \pm 1.9 ;{ }^{*} p<0.02 ; n=5\right)$, although it was not different in the presence of $\mathrm{Cd}^{2+}$ and Ni ${ }^{2+}$ (before, $0.5 \pm 0.1 \mathrm{~Hz}$; after NA, $1.3 \pm 0.7 \mathrm{~Hz} ; p>0.3$ ). The holding potential was $0 \mathrm{mV}$.

We investigated this possibility by recording activity elicited by stimulation of the VN (see Materials and Methods).

Stimulation of the VN layer evoked a long-lasting $(>500 \mathrm{~ms})$ EPSP in M/TCs. The stimulus intensity was adjusted so that the EPSP triggered one or several action potentials (Fig. 7A). The first evoked spike occurred with a latency of $22.6 \pm 2.4 \mathrm{~ms}$ (range, $11.2-37.6 \mathrm{~ms} ; 12$ trials, 3 cells). The $\alpha 1$ adrenergic agonist PE ( 30 $\mu \mathrm{M}, 2.5 \mathrm{~min}$ ) produced a long-lasting, reversible decrease in the number of spikes induced by stimulation of the $\mathrm{VN}$ (Fig. 7A, top, $B)$. This decrease in the number of spikes was accompanied by an
A

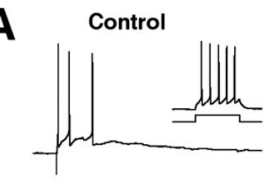

In prazosin
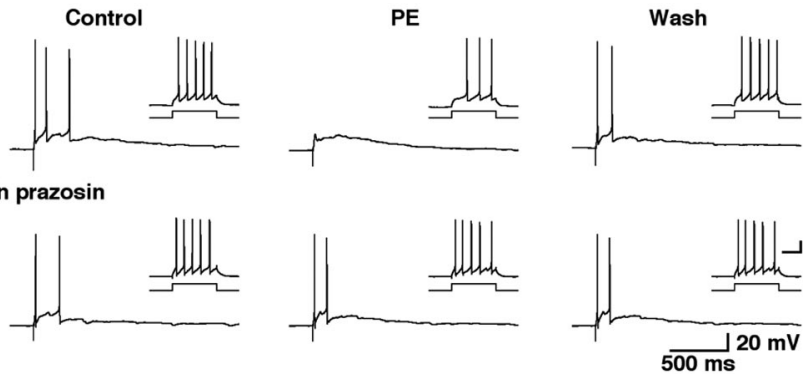

B

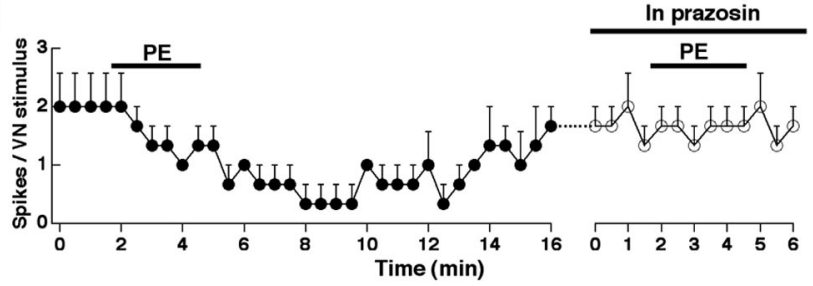

Figure 7. Activation of $\alpha 1$ adrenergic receptors depresses the input from vomeronasal nerve. $\boldsymbol{A}$, Action potentials were evoked by stimulation of the VN layer (see Materials and Methods). Application of PE ( $30 \mu \mathrm{m}, 2.5 \mathrm{~min})$ produced a long-lasting decrease in the number of stimulus-evoked action potentials. Inset, In the same cell, the number of spikes produced by a depolarizing current is reduced ( $500 \mathrm{~ms}, 50 \mathrm{pA}$ ). Bottom row, Prazosin ( $300 \mathrm{~nm}$ ) completely blocked the inhibitory effect of PE on the action potentials evoked by VN stimulation, as well as the activity in response to the intracellular depolarizing current (inset calibration: $1 \mathrm{~s}, 20 \mathrm{mV}$ ). $\boldsymbol{B}$, Time course of the effect of $P E$ on action potentials evoked by stimulation in the vomeronasal nerve layer. $\mathrm{PE}(30 \mu \mathrm{m}, 2.5 \mathrm{~min})$ produced a long-lasting, reversible depression in the number of action potentials evoked by VN stimulation. This effect was completely blocked by $300 \mathrm{~nm}$ prazosin (applied $\sim 20$ min; dotted line).

increase in the latency (range, 19.2-210.4 ms; $71.3 \pm 16.1 \mathrm{~ms} ; p<$ 0.02 ). Subsequent application of the selective $\alpha 1$ adrenergic antagonist prazosin ( $300 \mathrm{nM}$ ) completely blocked the effect of PE on the number of spikes (Fig. 7A, bottom, $B$ ) and the latency (before, $21.3 \pm 3.5 \mathrm{~ms}$; after, $22.7 \pm 3.5 \mathrm{~ms}$ ). Similarly, as observed with $\mathrm{NA}$, application of PE also decreased the frequency of firing induced by a direct depolarizing current pulse in the cell (before, $13.3 \pm 2.1 \mathrm{~Hz}$; after PE, $10.9 \pm 2.1 ; p<0.02 ; n=4$ ) (Fig. $7 A$, insets in top row), and this effect was completely blocked by prazosin (before, $13.8 \pm 2.4 \mathrm{~Hz}$; after PE, $14 \pm 2.4$ ) (Fig. $7 \mathrm{~A}$, insets in bottom row). These results are in agreement with the increase in inhibitory tone onto M/TCs as result of $\alpha 1$ adrenergic receptor activation.

\section{Discussion}

We have shown here that NA, acting through $\alpha 1$ adrenergic receptors, enhances the inhibitory tone of the output neurons in the AOB. NA decreased the firing rate of M/TCs and decreased the response of these cells to direct current stimulation, as well as activity evoked by stimulation of the VN. This overall inhibition of M/TCs was attributable to an enhancement of inhibitory transmission. NA greatly increased both the frequency of mIPSCs as well as the evoked inhibitory GABA currents induced by direct stimulation of granule cells. Because this leads to a decreased excitability of output neurons, our results are contrary to current models of the role of increased NA at mating, which predict a decrease in GABA release and an overall increased excitability.

The olfactory bulb receives a prominent adrenergic input from the locus ceruleus, and adrenergic modulation of the olfactory bulb is thought to be important in higher olfactory processing (Shipley et al., 1985). Several studies have indicated that noradrenergic activity excites M/TCs in the MOB. These observations include decreased dendrodendritic inhibition in the tur- 
tle olfactory bulb (Jahr and Nicoll, 1982), direct excitatory action on $\mathrm{M} / \mathrm{TC}$ by activation of $\alpha 1$ adrenergic receptors in rat (Hayar et al., 2001), decreased inhibitory transmission in cultured olfactory bulb cells by $\alpha 2$ adrenergic receptors (Trombley and Shepherd, 1992), and excitation of M/TCs by stimulation in the locus ceruleus or iotophoretic application of NA in the MOB (Ciombor et al., 1999). In addition, a few studies in the AOB have suggested that NA could have a similar action as in the MOB (Brennan et al., 1995). Thus, our observations on the cellular action of NA in the AOB were unexpected. However, other studies have shown an inhibitory action of NA in the MOB (Salmoiraghi et al., 1964; McLennan, 1971; Perez et al., 1987; Mouly et al., 1995; Okutani et al., 1998). In particular, the in vivo studies in cat of McLennan (1971) showed that the inhibitory action of NA was sensitive to bicuculline, indicating that they were mediated by increase of GABAergic transmission, as is the case in our studies. Additionally, Mouly and Ravel (1995) showed increased $\alpha 1$-mediated inhibition of M/TCs in evoked field potential recordings, and the inhibition observed by Perez et al. (1987) by locus ceruleus stimulation was sensitive to prazosin. Moreover, the actions of NA that we observed in the $\mathrm{AOB}$ are reminiscent of NA action in other brain regions and spinal cord. Most prominently, NA facilitates GABAergic transmission in stellate cells of the cerebellum (Llano and Gerschenfeld, 1993; Kondo and Marty, 1998), amygdala (Braga et al., 2004), sensorimotor cortex (Bennett et al., 1998), ventral bed nucleus of the stria terminalis (Dumont and Williams, 2004), and hypothalamus in the brain and in the substantia gelatinosa of the spinal cord (Baba et al., 2000). In our studies, the increase in mIPSC frequency was mediated by activation of $\alpha 1$ adrenergic receptors. These results are in agreement with in situ hybridization experiments that show high expression levels of $\alpha 1$ adrenergic receptors, in particular the $\alpha 1_{\mathrm{A}}$ subtype, in the AOB (McCune et al., 1993; Pieribone et al., 1994; Day et al., 1997; Domyancic and Morilak, 1997). Interestingly, NA also increases the GABA mIPSC frequency by acting on $\alpha 1$ adrenergic receptors in the spinal cord and in the basolateral amygdala (Braga et al., 2004).

It is noteworthy that, in the MOB, the cholinergic system, like the noradrenergic system, has also been proposed to participate in memory formation (Ravel et al., 1992, 1994), and both systems seem to exhibit a similar dual excitatory/inhibitory action on $\mathrm{M} / \mathrm{TC}$. In the MOB, cholinergic activity produces direct depolarization of M/TCs through nicotinic receptor activation, and muscarinic receptor activity on granule cells increases GABA inhibitory transmission (Castillo et al., 1999). Similarly, noradrenergic activation produces inhibition and excitation of M/TCs in the MOB (Mouly et al., 1995; Okutani et al., 1998; Ciombor et al., 1999; Hayar et al., 2001). However, although the cholinergic effects in the AOB are similar to those observed in the MOB (R. C. Araneda, unpublished results), in the AOB the overall effect of NA was mainly inhibitory, suggesting that the mechanisms by which the noradrenergic system participates in memory formation in the AOB may be different than in the MOB.

Noradrenergic activity could modulate GABA release from granule cells or periglomerular cells, or both. However, in the $\mathrm{AOB}$ the majority of the noradrenergic fibers are found in the internal plexiform layer, which contains the dendrites of granule cells, and in the granule cell layer. Virtually no noradrenergic innervation in the glomerular layer is observed (McLean et al., 1989). Together with the high levels of $\alpha 1_{\mathrm{A}}$ adrenergic receptor subtype mRNA found in granule cells of the AOB (see above), the increase in GABA release produced by NA seems likely to have occurred at the granule cell-M/TC dendrodendritic synapses.
Most important in this regard, the release of GABA evoked by direct stimulation of granule cells with glutamate stimulation was greatly enhanced by NA. Interestingly, quantification of neurotransmitter levels in the $\mathrm{AOB}$ using in vivo microdialysis has shown that, during post-mating, concurrent with high levels of $\mathrm{NA}$, the release of GABA induced by a glutamate challenge was increased (Brennan et al., 1995).

In the presence of NA, mIPSCs increased in frequency but without any significant change in their amplitude, strongly suggesting a presynaptic effect. In addition, NA did not affect the size of the responses to GABA. Thus, we believe that the small difference in the cumulative amplitude distributions was attributable to an increase in the number of smaller events and the low frequency of mIPSC in control versus NA, which could have biased the analysis. It should be noted that a similar effect has been observed with the muscarinic augmentation of mIPSC frequency in the MOB (Castillo et al., 1999). Moreover, our results are in agreement with the reported effects of NA at other synapses in the CNS in which NA has been shown to exert either presynaptic enhancement or depression of excitatory and inhibitory transmission. Both $\alpha$ and $\beta$ adrenergic receptors have been shown to mediate these presynaptic effects (Llano and Gerschenfeld, 1993; Braga et al., 2004). In most of these instances, the effect of NA in synaptic transmission enhancement was resistant to blockers of voltage-dependent $\mathrm{Ca}^{2+}$ channels, and a direct effect of NA in the presynaptic secretory machinery was postulated. In contrast, the effect of NA in the AOB was sensitive to voltage-gated $\mathrm{Ca}^{2+}$ channel blockers, suggesting that NA may modulate the activity of such channels in the granule cell dendrites, thereby increasing the release of GABA. This possibility seems likely because $\alpha 1$ adrenergic receptors acting though $\mathrm{G}_{\mathrm{q} / 11}$ have been shown to modulate $\mathrm{Ca}^{2+}$ channels (Zhong and Minneman, 1999). Additionally, activation of $\alpha 1$ adrenergic receptors by NA has been shown to increase intracellular $\mathrm{Ca}^{2+}$ in cultured olfactory bulb interneurons (Tani et al., 1992).

Although the overall effect of adrenergic activity on the membrane potential of M/TCs was rather small, our results suggest that a large increase in GABA inhibitory currents could act as a "shunt," not only for the excitatory sensory input onto M/TC but also for the propagation of depolarizing activity through lateral dendrites. The propagation of this depolarizing activity is thought to be responsible for the release of glutamate at dendrodendritic synapses, which in turn causes release of GABA from granule cells. Thus, a decrease in the ability to depolarize secondary dendrites in the presence of adrenergic activity could result in an apparent decrease in dendrodendritic inhibition (i.e., less dendrodendritic synapses are activated because of the shunting). Conversely, the large enhancement of GABA inhibitory currents we report here could have effects on other properties of the AOB circuitry.

Our results indicate that the actions of NA in the AOB may be more complex than previously appreciated (Kaba and Nakanishi, 1995; Brennan, 2004). The inhibitory action we described could have an important physiological role. The increase in GABAergic transmission with the accompanying inhibition of $\mathrm{M} / \mathrm{TCs}$ could increase the signal-to-noise ratio for the M/TCs, consequently allowing only strong (salient) stimuli to overcome this inhibition. It thus appears that a more complex mechanism than simple excitation during mating is needed to explain the role of the noradrenergic system during memory formation in the Bruce effect. 


\section{References}

Baba H, Shimoji K, Yoshimura M (2000) Norepinephrine facilitates inhibitory transmission in substantia gelatinosa of adult rat spinal cord. 1. effects on axon terminals of GABAergic and glycinergic neurons. Anesthesiology 92:473-484.

Bennett BD, Huguenard JR, Prince DA (1998) Adrenergic modulation of GABAA receptor-mediated inhibition in rat sensorimotor cortex. J Neurophysiol 79:937-946.

Braga MF, Aroniadou-Anderjaska V, Manion ST, Hough CJ, Li H (2004) Stress impairs alpha(1A) adrenoceptor-mediated noradrenergic facilitation of GABAergic transmission in the basolateral amygdala. Neuropsychopharmacology 29:45-58.

Brennan PA (2004) The nose knows who's who: chemosensory individuality and mate recognition in mice. Horm Behav 46:231-240.

Brennan PA, Keverne EB (1997) Neural mechanisms of mammalian olfactory learning. Prog Neurobiol 51:457-481.

Brennan PA, Kendrick KM, Keverne EB (1995) Neurotransmitter release in the accessory olfactory bulb during and after the formation of an olfactory memory in mice. Neuroscience 69:1075-1086.

Bruce HM (1960) A block to pregnancy in the mouse caused by proximity of strange males. J Reprod Fertil 1:96-103.

Castillo PE, Carleton A, Vincent JD, Lledo PM (1999) Multiple and opposing roles of cholinergic transmission in the main olfactory bulb. J Neurosci 19:9180-9191.

Ciombor KJ, Ennis M, Shipley MT (1999) Norepinephrine increases rat mitral cell excitatory responses to weak olfactory nerve input via alpha-1 receptors in vitro. Neuroscience 90:595-606.

Day HE, Campeau S, Watson Jr SJ, Akil H (1997) Distribution of alpha 1a-, alpha 1b- and alpha 1d-adrenergic receptor mRNA in the rat brain and spinal cord. J Chem Neuroanat 13:115-139.

Domyancic AV, Morilak DA (1997) Distribution of alpha1A adrenergic receptor mRNA in the rat brain visualized by in situ hybridization. J Comp Neurol 386:358-378.

Dumont EC, Williams JT (2004) Noradrenaline triggers GABA A $_{\mathrm{A}}$ inhibition of bed nucleus of the stria terminalis neurons projecting to the ventral tegmental area. J Neurosci 24:8198-8204.

Firestein S (2001) How the olfactory system makes sense of scents. Nature 413:211-218

Halpern M, Martinez-Marcos A (2003) Structure and function of the vomeronasal system: an update. Prog Neurobiol 70:245-318.

Hayar A, Heyward PM, Heinbockel T, Shipley MT, Ennis M (2001) Direct excitation of mitral cells via activation of alpha1-noradrenergic receptors in rat olfactory bulb slices. J Neurophysiol 86:2173-2182.

Hayashi Y, Momiyama A, Takahashi T, Ohishi H, Ogawa-Meguro R, Shigemoto R, Mizuno N, Nakanishi S (1993) Role of a metabotropic glutamate receptor in synaptic modulation in the accessory olfactory bulb. Nature 366:687-690.

Isaacson JS, Strowbridge BW (1998) Olfactory reciprocal synapses: dendritic signaling in the CNS. Neuron 20:749-761.

Jahr CE, Nicoll RA (1982) Noradrenergic modulation of dendrodendritic inhibition in the olfactory bulb. Nature 297:227-229.

Jia C, Chen WR, Shepherd GM (1999) Synaptic organization and neurotransmitters in the rat accessory olfactory bulb. J Neurophysiol 81:345-355.

Kaba H, Huang GZ (2005) Long-term potentiation in the accessory olfactory bulb: a mechanism for olfactory learning. Chem Senses 30 [Suppl 1]:i150-i151.

Kaba H, Keverne EB (1988) The effect of microinfusions of drugs into the accessory olfactory bulb on the olfactory block to pregnancy. Neuroscience 25:1007-1011.

Kaba H, Nakanishi S (1995) Synaptic mechanisms of olfactory recognition memory. Rev Neurosci 6:125-141.

Kondo S, Marty A (1998) Differential effects of noradrenaline on evoked, spontaneous and miniature IPSCs in rat cerebellar stellate cells. J Physiol (Lond) 509:233-243.
Llano I, Gerschenfeld HM (1993) Beta-adrenergic enhancement of inhibitory synaptic activity in rat cerebellar stellate and Purkinje cells. J Physiol (Lond) 468:201-224.

McCune SK, Voigt MM, Hill JM (1993) Expression of multiple alpha adrenergic receptor subtype messenger RNAs in the adult rat brain. Neuroscience 57:143-151.

McLean JH, Shipley MT, Nickell WT, Aston-Jones G, Reyher CK (1989) Chemoanatomical organization of the noradrenergic input from locus coeruleus to the olfactory bulb of the adult rat. J Comp Neurol 285:339-349.

McLennan H (1971) The pharmacology of inhibition of mitral cells in the olfactory bulb. Brain Res 29:177-184.

Meisami E, Bhatnagar KP (1998) Structure and diversity in mammalian accessory olfactory bulb. Microsc Res Tech 43:476-499.

Mouly AM, Elaagouby A, Ravel N (1995) A study of the effects of noradrenaline in the rat olfactory bulb using evoked field potential response. Brain Res 681:47-57.

Nicoll RA (1969) Inhibitory mechanisms in the rabbit olfactory bulb: dendrodendritic mechanisms. Brain Res 14:157-172.

Okutani F, Kaba H, Takahashi S, Seto K (1998) The biphasic effects of locus coeruleus noradrenergic activation on dendrodendritic inhibition in the rat olfactory bulb. Brain Res 783:272-279.

Perez H, Hernandez A, Almli CR (1987) Locus coeruleus stimulation modulates olfactory bulb evoked potentials. Brain Res Bull 18:767-770.

Pieribone VA, Nicholas AP, Dagerlind A, Hokfelt T (1994) Distribution of $\alpha 1$ adrenoceptors in rat brain revealed by in situ hybridization experiments utilizing subtype-specific probes. J Neurosci 14:4252-4268.

Rall W, Shepherd GM, Reese TS, Brightman MW (1966) Dendrodendritic synaptic pathway for inhibition in the olfactory bulb. Exp Neurol 14:44-56.

Ravel N, Vigouroux M, Elaagouby A, Gervais R (1992) Scopolamine impairs delayed matching in an olfactory task in rats. Psychopharmacology (Berl) 109:439-443.

Ravel N, Elaagouby A, Gervais R (1994) Scopolamine injection into the olfactory bulb impairs short-term olfactory memory in rats. Behav Neurosci 108:317-324.

Rosser AE, Keverne EB (1985) The importance of central noradrenergic neurones in the formation of an olfactory memory in the prevention of pregnancy block. Neuroscience 15:1141-1147.

Salmoiraghi GC, Bloom FE, Costa E (1964) Adrenergic mechanisms in rabbit olfactory bulb. Am J Physiol 207:1417-1424.

Schoppa NE, Urban NN (2003) Dendritic processing within olfactory bulb circuits. Trends Neurosci 26:501-506.

Schoppa NE, Kinzie JM, Sahara Y, Segerson TP, Westbrook GL (1998) Dendrodendritic inhibition in the olfactory bulb is driven by NMDA receptors. J Neurosci 18:6790-6802.

Shepherd GM, Greer CA (1998) Olfactory bulb. In: The synaptic organization of the brain, Ed 4 (Shepherd GM, ed), pp 159-204: Oxford UP.

Shipley MT, Halloran FJ, de la Torre J (1985) Surprisingly rich projection from locus coeruleus to the olfactory bulb in the rat. Brain Res 329:294-299.

Takami S, Graziadei PP (1991) Light microscopic Golgi study of mitral/ tufted cells in the accessory olfactory bulb of the adult rat. J Comp Neurol 311:65-83.

Tani A, Yoshihara Y, Mori K (1992) Increase in cytoplasmic free $\mathrm{Ca}^{2+}$ elicited by noradrenalin and serotonin in cultured local interneurons of mouse olfactory bulb. Neuroscience 49:193-199.

Taniguchi M, Kaba H (2001) Properties of reciprocal synapses in the mouse accessory olfactory bulb. Neuroscience 108:365-370.

Trombley PQ, Shepherd GM (1992) Noradrenergic inhibition of synaptic transmission between mitral and granule cells in mammalian olfactory bulb cultures. J Neurosci 12:3985-3991.

Zhong H, Minneman KP (1999) Alphal-adrenoceptor subtypes. Eur J Pharmacol 375:261-276. 